\title{
Multifunctional Semi-interpenetrating Superabsorbents from Graft Polymerization of Acrylic Acid on Cellulose in Presence of Fulvic Acid as Potential Slow Release Devices of Soil Nutrients
}

\author{
Mohamed B. M. Ghazy ${ }^{1}$, Farag Abd El-Hai ${ }^{1}$, Magdy F. Mohamed ${ }^{1}$, Hisham A. Essawy ${ }^{2 \star}$ \\ ${ }^{1}$ Department of Chemistry, Faculty of Science, El- Azhar University, Nasr city, Cairo, EGYPT. \\ ${ }^{2}$ Department of Polymers and Pigments, National Research Centre, Dokki 12622, Cairo, EGYPT. \\ "Corresponding author: hishamessawy@yahoo.com
}

\begin{abstract}
Grafting polymerization of acrylic acid (AA) was undertaken onto cellulose powder (Cell) in presence of potassium fulvate (KF) to produce semi-interpenetrating network structures. The grafting efficiency (GE) and grafting yield (GY) were studied as and indicated that the grafting process was not influenced in presence of KF. KF was expected to be incorporated into the cellulose backbone in the same course of the graft polymerization via polycondensation with groups from cellulose and monomer. The simultaneous graft polymerization of acrylic acid and polycondensation processes of all components allows formation of a more chemically active semi-interpenetrating network structure. Successful incorporation of KF to the network structure was predicted from fourier transform infrared spectroscopy (FTIR) while enhanced $\mathrm{Cu}^{2+}$ uptake confirmed the better chemical activity with respect to the same network prepared in absence of KF. Furthermore, the wide variation of the swelling potential as a function of the $\mathrm{pH}$ further corroborates the insertion of KF to the network structure. Imaging with scanning electron microscopy (SEM) indicated morphological alteration on the surface which might be related to the KF anchoring to the cellulose backbone. The developed superabsorbents showed increment in the water absorption both in distilled water and salted solutions as well. The newly developed superabsorbent was applied as a support for soil nutrients and their controlled release in soil was studied. The results proved efficiency of the superabsorbent to warrant appropriate release of the nutrients according to the time regulations set by European Committee of Normalization (ECN). Improved water retention was also an additional advantage.
\end{abstract}

Indexing terms/Keywords: superabsorbents, cellulose, acrylic acid, fulvic acid, grafting, soil fertilizers, slow release.

\section{Council for Innovative Research}

Peer Review Research Publishing System

\section{Journal: Journal of Advances in Chemistry}

Vol. 12 , No. 2

editor@cirjac.com

www.cirjac.com 


\section{INTRODUCTION}

Crosslinked polymers with a network structure and high content of hydrophilic functional groups are denoted as hydrogels. The great potential to absorb significant amount of water distinguishes these materials from others [1-3]. This advantage expanded the applications of such materials in horticulture and agricultural fields, and as carriers for drug delivery systems and devices for controlled release [4-9]. The preparation and characterization of polysaccharides for possible use as superabsorbents was studied intensively as a result of their biocompatibility and biodegradability [10, 11]. Natural biopolymers from cellulose materials are interesting because they refer to renewable resources in addition to their nontoxicity [12]. Their availability permits easier use in wide range of applications. Vinyl monomers were grafted onto polysaccharides in the presence of crosslinking agents to cause crosslinking of the grafted chains which leads to development of a network structure and this allows for advancing their properties [13, 14]. Cheap superabsorbents were fabricated by grafting of monomers such as acrylic acid and acrylamide onto varieties of backbones including starch [1517], cellulose [18-20], carrageenan [21], lignin [22, 23], chitosan [24-26], wheat straw [27-29], sugarcane bagasse [30], pineapple peel [31], salep [32] and guar gum [33].

Major applications of the developed superabsorbents are slow release devices particularly for soil nutrients [34, 35]. Humic substances are abundant organic materials bearing multifunctional aliphatic and aromatic constituents and a high content of functional groups [36]. Thus, they are beneficial materials for regulating the plant growth and in the root developments. The photosynthesis process is enriched by their presence accompanied by associated improvement of the soil cluster structure which helps absorption of nutrient elements [37, 38]. Likewise, fulvic acid contains over $70 \%$ of humic substances, and usually carries over 70 minerals and trace elements as part of its molecular complexes [39]. These structures are motivating because of their lower molecular weights, stronger acidities, and higher solubility in water as compared to humic acids [40]. Simplistic solubility in both acidic and basic mediums is additional advantage which is quite the opposite of humic acid that is soluble in alkali but not in acids. The higher biological activity and more oxygen containing groups makes fluvic acid more imperative with respect to other humic substances [41].

Humic acids were elaborated as constituents in the course of preparation of superabsorbing materials [36, 37] in order to elevate the biological activity and broaden their applications thanks to the multifunctionality of the incorporated humic materials. These remarkable compensations of fulvic substances over similar humics lie beyond the suggestion of using them as candidates to replace the humics in formulations related to superabsorbents especially those prepared with target for use as devices for controlled release of soil nutrients. Accordingly employing a cellulose as backbone for grafting polymerization of acrylic acid in the presence of potassium persulfate (KPS) as an initiator and methylenebisacrylamide (MBA) as crosslinker while fulvic acid was additionally employed for improving properties like water absorbency and retention, which is expected to contribute better in controlled release applications of NPK as soil nutrients.

\section{EXPERIMENTAL}

\subsection{Materials}

Acrylic acid (AA) was purchased from Sigma-Aldrich, USA. Potassium persulfate (KPS) was obtained from Loba Chemie Co. India. N,N-methylenebisacrylamide (MBA) was ordered from Merck, Germany. Cellulose pure powder (Cell) and potassium hydroxide were supplied from Sd. fine Chem., India. Leonaridite was obtained from Black Earth Humic LP., Canada. Potassium dihydrogen phosphate and ammonium nitrate (denoted together as NPK) were bought from Fluka.

\subsection{Fulvic acid extraction from leonaridite}

Fulvic acid was prepared by extraction from the available raw material leonaridite. The process starts with addition of $0.1 \mathrm{M}$ of hydrochloric acid to leonaridite while stirring the obtained suspension at $60^{\circ} \mathrm{C}$ for one $\mathrm{h}$., then the solution was filtrated and the solid residue was recovered and washed several times with distilled water. The obtained filtrate was distilled under vacuum to get the fulvic acid as a light brown precipitate. Fulvic acid was neutralized and used as potassium salt [40].

\subsection{Preparation of the (Cell-g-PAA)/KF superabsorbent composite}

$5.0 \mathrm{~g}$ Cell (25 wt. \% with respect to AA) was suspended in $30 \mathrm{ml}$ distilled water and the resulting slurry was transferred into a three-neck flask, equipped with a stirrer, reflux condenser, nitrogen line and thermometer. The slurry was heated to 70 ${ }^{\circ} \mathrm{C}$ for $30 \mathrm{~min}$ and then purged with nitrogen for $15 \mathrm{~min}$. to remove the dissolved oxygen from the system. KPS was added as an initiator (1.0 wt. \% with respect to $A A$ ) after being dissolved $10 \mathrm{ml}$ of distilled water and introduced to the Cell suspension to provoke radicals formation. $15 \mathrm{~min}$. later, a solution was added including $20.0 \mathrm{~g}$ of partially neutralized AA, 1.0 wt. \% with respect to AA of the crosslinker MBA as well as $0-10 \mathrm{wt}$. \% with respect to AA of potassium fulvate which was taken as a variable. The water bath was kept at $70{ }^{\circ} \mathrm{C}$ for $3 \mathrm{~h}$. to ensure achievement of the polymerization. The product was dehydrated with excessive amount of methanol and subjected to drying at $70{ }^{\circ} \mathrm{C}$ until constant weight is reached. $1.0 \mathrm{~g}$ of the obtained dried crude product was ground into a fine powder and stirred in distilled water at room temperature for $24 \mathrm{~h}$. to eliminate the ungrafted polyacrylic acid and the mixture was filtered to isolate the graft copolymer. The graft copolymer was washed several times with distilled water and dehydrated additionally with methanol. Drying the graft copolymer was accomplished at $65{ }^{\circ} \mathrm{C}$ until constant weight. The grafting efficiency (GE) and yield (GY) were calculated using eqs. 1 and 2 [13, 42-44].

$$
\begin{aligned}
& \text { GE \% }=\left[\left(w_{1}-w\right) /\left(w_{2}-w\right)\right] \times 100 \\
& \text { GY \% }=\left[\left(w_{2}-w\right) / w\right] \times 100
\end{aligned}
$$


where $w, w_{1}$ and $w_{2}$ are the weights of cellulose, purified graft copolymer and total weight of crude polymer, respectively.

\subsection{Characterizations}

FTIR spectrophotometer (Jasco, Model 6100, Japan) was used for recording the IR spectra in the range $500-4000 \mathrm{~cm}^{-1}$ at a resolution of $4 \mathrm{~cm}^{-1}$. Dried samples were blended with $\mathrm{KBr}$ and pressed into discs before acquisition. The morphological features of samples were examined using SEM (JSM-5500LV, JEOL, Ltd.) operated under vacuum, after being gold coated with a sputter Coater (SPI-Module).

\subsection{Water sorption measurements}

A specific weight of the superabsorbent was immersed in distilled water at room temperature for $24 \mathrm{~h}$. The swollen samples were removed from the medium by filtration. The water absorbency, $Q(\mathrm{~g} / \mathrm{g})$, of the superabsorbent composites was determined by taking the weight difference of the samples before and after immersion in the water and applying the following equation:

$$
Q=\left(m_{2}-m_{1}\right) / m_{1}
$$

Where $m_{1}$ and $m_{2}$ are the weights of the dry and swollen samples $(g)$, respectively.

\subsection{Swelling at various $\mathrm{pH}$}

A series of solutions with different $\mathrm{pH}$ values were prepared using dilute $\mathrm{KOH}$ and $\mathrm{HCl}$ solutions to adjust the $\mathrm{pH}$. Afterwards, $0.1 \mathrm{~g}$ of each superabsorbent polymer was added in the appropriate solution for $24 \mathrm{~h}$. in order to measure the swelling capacity according to Eq. (3).

\subsection{Swelling in salt solutions}

The swelling capacities of the superabsorbent polymers were determined in $0.15 \mathrm{M}$ solutions of $\mathrm{NaCl}, \mathrm{KCl}, \mathrm{NH} \mathrm{Cl}_{2} \mathrm{MgCl}_{2}$, $\mathrm{MnCl}_{2}$ and $\mathrm{FeCl}_{3}$ then the swelling capacity was calculated after Eq. (3).

\subsection{Copper ion sorption}

Adsorption of $\mathrm{Cu}^{2+}$ was determined by atomic absorption (AA 200 series, Agilent, USA). Sorption was carried out by stirring $0.1 \mathrm{~g}$ of superabsorbent polymer for $3 \mathrm{~h}$. in $100 \mathrm{ml}$ solution containing variable concentration of copper sulfate $(1000,750,500,250$ and $100 \mathrm{mg} / \mathrm{L})$. After filtration, the remaing metal ions in the filtrate were determined using the AA $[36,43]$.

\subsection{Loading of NPK to the superabsorbent}

The loading of potassium dihydrogen phosphate and ammonium nitrate was achieved by immersing a pre-weighed amount of the dry superabsorbent into $500 \mathrm{ml}$ of aqueous solution containing potassium dihydrogen phosphate $(0.03$ $\left.\mathrm{molL}^{-1}\right)$ and ammonium nitrate $\left(0.03 \mathrm{molL}^{-1}\right)$ for $24 \mathrm{~h}$. Subsequently, the swollen gel was dried at $40{ }^{\circ} \mathrm{C}$ for 3 days [28]. The loading percentage was calculated using Eq. (4):

$$
\text { Loading } \%=\left[w_{1}-w_{0}\right] / w_{1} \times 100
$$

where $w_{0}$ and $w_{1}$ are the weights of unloaded and loaded dry gels, respectively.

\subsection{Controlled release of NPK in soil}

The release of $\mathrm{N}, \mathrm{P}$ and $\mathrm{K}$ from Cell-g-PAA/KF in sandy soil as a porous material was demonstrated by conducting release experiments. A soil column was built by filling $100 \mathrm{~g}$ of air-dried sand $(840 \mu \mathrm{m})$ into PVC pipe of $45 \mathrm{~mm}$ internal diameter as a holder after homogeneously mixing with $1.0 \mathrm{~g}$ of the superabsorbent. The lower opening of the PVC pipe was sealed by a nylon fabric and water was dropped slowly from the upper opening of the pipe using using a 25-ml burette until saturation then the water was charged at a rate of one drop every $10 \mathrm{~s}$. Afterwards, $10 \mathrm{ml}$ of the soil water was collected after $1,3,5,10,15,20,25,30$, and 60 days of incubation. The NPK components were measured separately using element analyzer instrument (Elementar Vario El III, Germany) in case of N, colorimetric method based on molybdovanadate reagent using a spectrophotometer $(\mathrm{HACH}$, model $\mathrm{DR} / 2010)$ in case of $\mathrm{P}$ while atomic absorption (AA 200 series, Agilent, USA) was employed in case of K [45, 46].

\subsection{Water retention measurements}

In a beaker, $2.0 \mathrm{~g}$ of Cell-g-PAA/KF-NPK was mixed with $100 \mathrm{~g}$ of dry sandy soil granules (below $840 \mu \mathrm{m}$ diameter) and added to a $200 \mathrm{ml}$ distilled water. The beaker was stored at a temperature and relative humidity of $25{ }^{\circ} \mathrm{C}$ and $31 \%$, respectively. The overall weight was followed every 4 days for a period of 4 weeks. A controlled sample was prepared without the superabsorbent polymer. The water evaporation was calculated according to eq. 5:

$$
\text { Water retention }(\%)=100-\left[\left(w_{2}-w_{1}\right) / 200\right] \times 100
$$

Where $w_{2}$ is the initial overall weight of the beaker components and $w_{1}$ is the weight after the predetermined time intervals $[47,48]$. 


\section{RESULTS AND DISCUSSION}

\subsection{Characterization of Cell-g-PAA/KF superabsorbent composite}

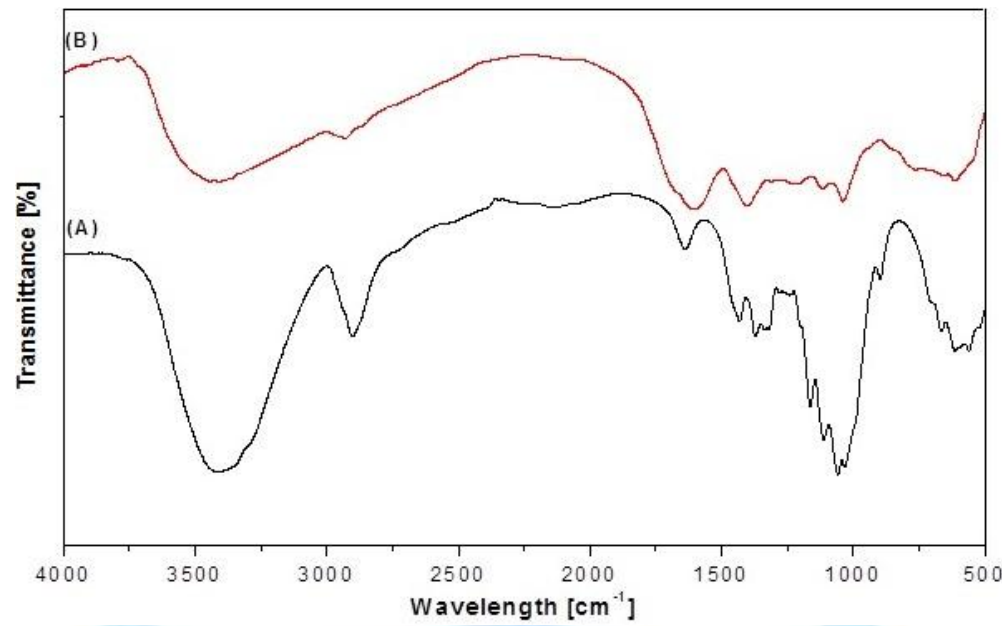

Fig. 1: FT-IR spectra of (A) cellulose, (B) potassium fulvate.

The characteristic IR bands corresponding to cellulose can be detected at 3414, 1638, 1336 and $1111 \mathrm{~cm}^{-1}$ which belong to $\mathrm{OH}$ stretching. Additional peaks that belong to $\mathrm{CH}$ stretching were also detected at 2901,1371 and $896 \mathrm{~cm}^{-1}$. The bands at 1430, 1320 and $1031 \mathrm{~cm}^{-1}$ are ascribed to $\mathrm{CH}_{2}$ along with bands at 1162 and $1057 \mathrm{~cm}^{-1}$ revealing C-O-C stretching (Fig. 1a). Potassium fulvate corresponding spectra was also recorded (Fig. 1b). A group of peaks appeared at $1670 \mathrm{~cm}^{-1}$ (C=O asymmetric stretching), $1038 \mathrm{~cm}^{-1}$ (C-O stretching) and $3000-3800 \mathrm{~cm}^{-1}$ (-OH or phenolic hydroxyls) are typical bands for KF. The peaks at $2930 \mathrm{~cm}^{-1}$ and $2850 \mathrm{~cm}^{-1}$ are additionally referring to $\mathrm{CH}$ and $\mathrm{CH}_{2}$, respectively. The bands at $1607 \mathrm{~cm}^{-1}$ and $714-761 \mathrm{~cm}^{-1}$ are indicative of aromatic $\mathrm{C}=\mathrm{C}$ and strongly $\mathrm{H}$-bonded carbonyls of conjugated ketones [49].

The resulting material from the grafting acrylic acid onto the cellulosic backbone was examined with IR spectroscopy (Fig 2a) which show emergence of signal at $2830 \mathrm{~cm}^{-1}\left(\mathrm{CH}_{2}\right.$ stretching of the grafted polyacrylic acid). Another peak appeared at $1625 \mathrm{~cm}^{-1}$ is indicative of $\mathrm{C}=\mathrm{O}$ sites on the grafted polyacrylic acid. The $\mathrm{OH}$ groups were assigned by broad bands at $3000-3800 \mathrm{~cm}^{-1}$ and this broadening is attributed to different environments of the hydroxyl groups originating from the cellulose and polyacrylic acid as well. The incorporation of KF during the grafting polymerization should haver modified the network structure as can be seen in Fig. 2b. The spectra is very similar to that of cell-g-PAA. However, a slight difference can be detected in the sense of reshaping at the region of $1650-1750 \mathrm{~cm}^{-1}$ of the carbonyl groups. The same can be noticed in the region of hydroxyl groups as a result of additional environment provided by the linked KF which became a permanent part of the interpenetrating network.

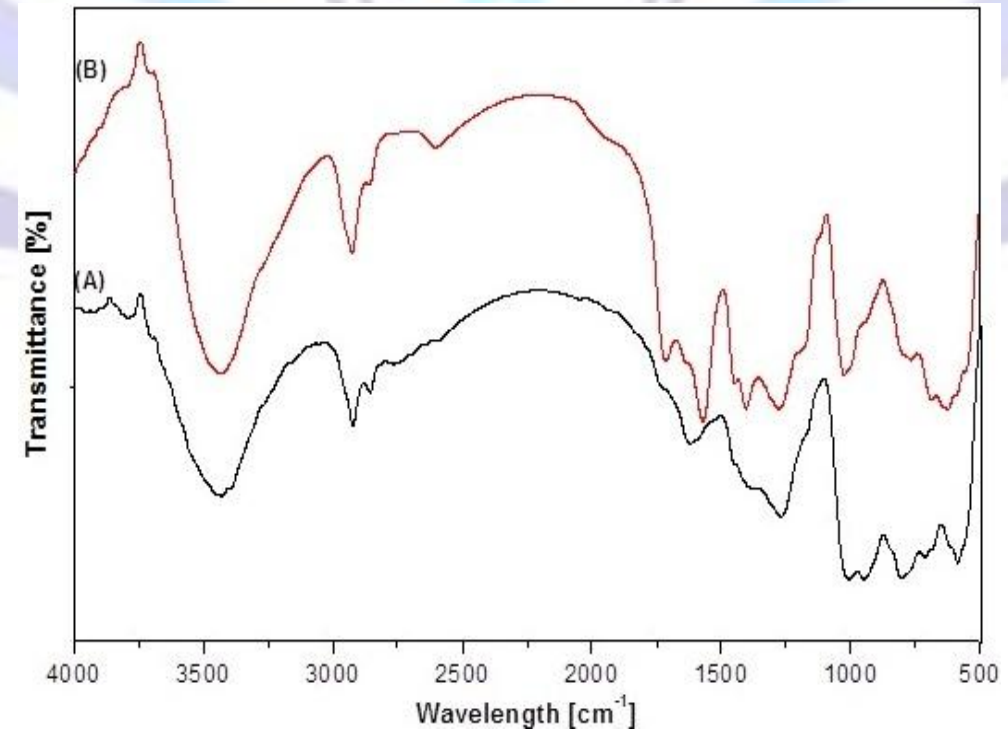

Fig. 2: FT-IR spectra of (A) Cell-g-PAA and (B) Cell-g- PAA/KF superabsorbent composite. 
3.2 Morphology of superabsorbent composites
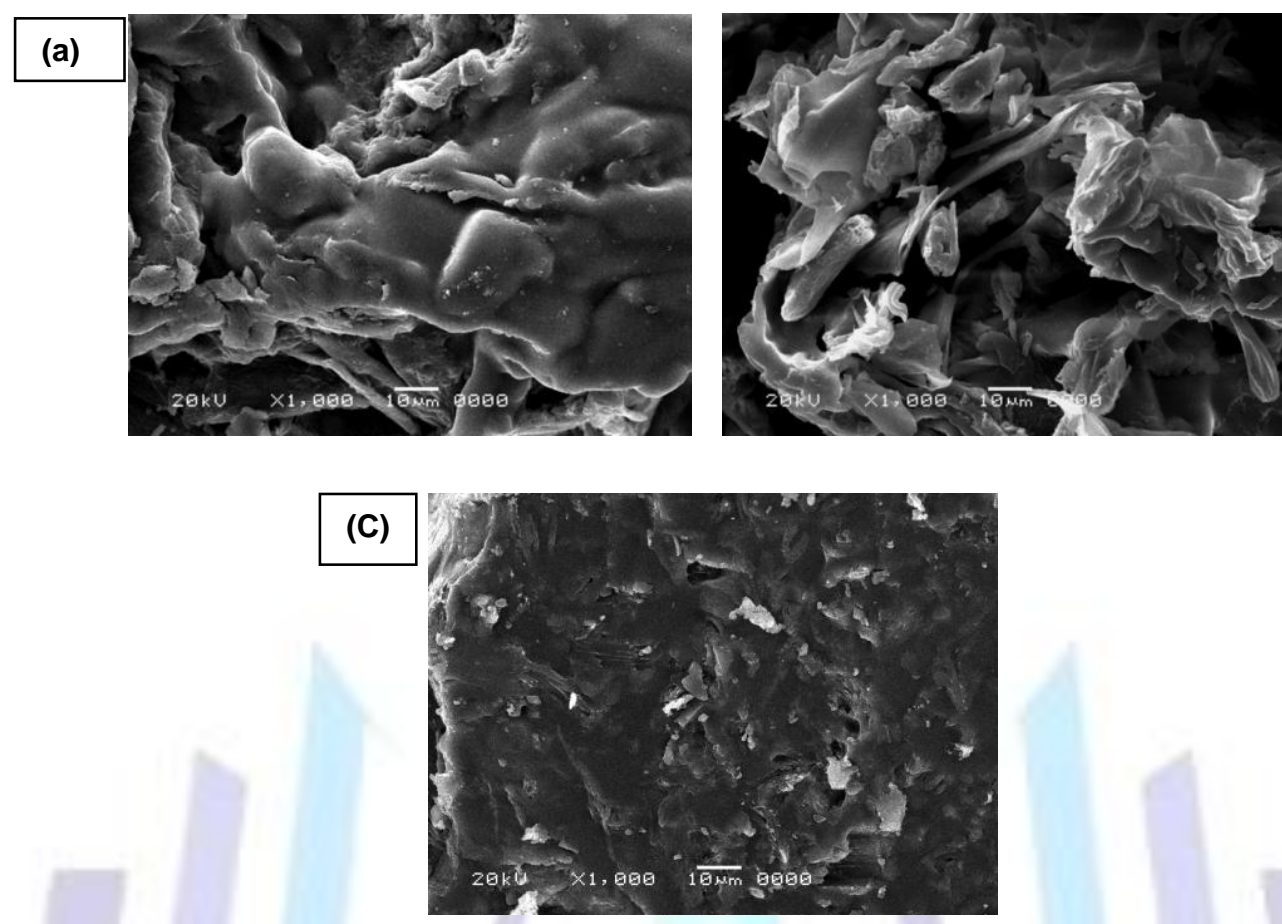

Fig. 3: SEM micrographs of (a) Cell-g-PAA, (b) Cell-g-PAA/KF, (C) Cell-g-PAA/KF-NPK superabsorbent composite.

SEM micrographs representing Cell-g-PAA, Cell-g-PAA/KF and Cell-g-PAA/KF-NPK are exhibited in Fig. 3. Obviously, the morphology of Cell-g-PAA shows a surface covered by grafted chains which is in accordance with a grafting process was undertaken at the surface of the cellulose. The density of the grafted chains increased obviously on the surface in the presence of KF, matching with a semi-interpenetrating network possessing some porosity (Fig. $3 \mathbf{b}$ ). The denser grafting in this case is expected to be favored by the KF. The NPK as fertilizer was loaded and some surficial traces can be detected on the surface (Fig. 3c).

\subsection{Effect of potassium fulvate content on the grafting parameters}

Table 1. Estimation of GE\% and GY\% for grafting of acrylic acid onto cellulose as a function of KF content.

\begin{tabular}{|c|c|c|c|c|c|c|}
\hline Cont. of KF, \% & $\mathbf{0}$ & $\mathbf{1 . 2 5}$ & $\mathbf{2 . 5}$ & $\mathbf{5}$ & $\mathbf{7 . 5}$ & $\mathbf{1 0}$ \\
\hline GE \% & 81.5 & 82 & 82.9 & 83 & 81.5 & 80 \\
\hline GY \% & 449 & 449.8 & 453.6 & 469.6 & 454.8 & 449.6 \\
\hline & & & & & & \\
\hline
\end{tabular}

Potassium fulvate was employed in this study to enrich the chemical activity of the resulting graft copolymer. The grafting process of acrylic acid on the cellulose backbone was taking place in presence and absence of KF and the impact of this addition on the grafting efficiency was studied and summarized in Table 1. A trivial difference was observed for the grafting efficiency which proves that the grafting process was not affected by the addition of KF. On the contrary, some increase in the grafting yield was associated to increasing levels of KF below 5 wt. \%. More than 5 wt. \% of KF caused an opposing effect on the grafting yield. The high content of hydrophilic groups after the functionalization of the graft copolymer with KF is thought to have favored the grafting yield by capturing more acrylic acid to the network via esterification reaction with its hydroxyl groups. However, homopolymerization of the acrylic acid was favored when KF content was above 5 wt. \% as a results of its water solvency and preference to react with the acrylic acid in the solution and this provides a reasonable explanation for decline in water sorption when the content of KF exceeds 5 wt. \%. Thus above $5 \mathrm{wt}$. \% the function groups are involved to a greater extent in polycondensation reactions which hampers the free radical graft copolymerization hence capacity of water absorption is expected to be affected as will be shown in a next section. 


\subsection{Effect of potassium fulvate content on the water sorption}

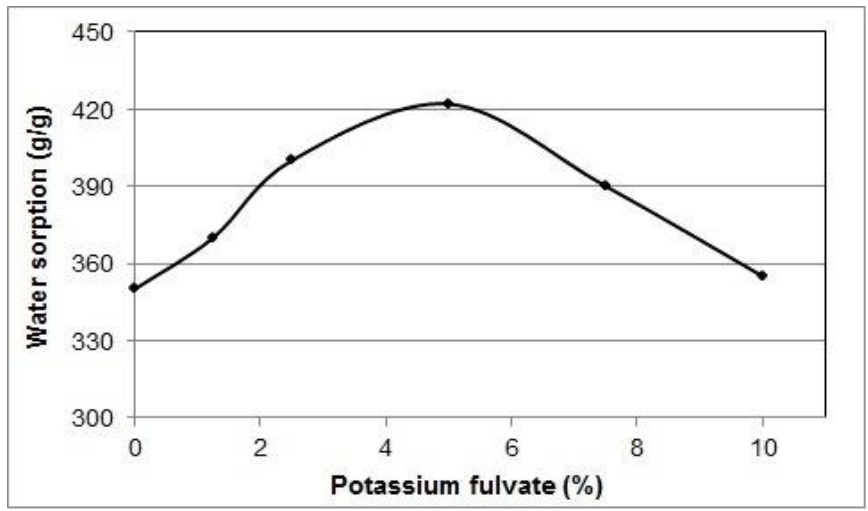

Fig. 4: The influence of potassium fulvate content on the water sorption of Cell-g-PAA.

Fig. 4 indicates a water absorption of $350 \mathrm{~g} / \mathrm{g}$ for cell-g-PAA alone. After the insertion of the fulvic acid, the water absorption increased gradually as a function of the fulvic acid content and reached maximum at 5 wt. \% reached maximum $(422 \mathrm{~g} / \mathrm{g})$ due to the acquired larger number of hydrophilic functional groups. Above this content of fulvic acid, the water sorption was adversely affected which might highlight the fulvic acid acts as a crosslinker and limits the porosity of the resulting superabsorbent. Nevertheless, this was explained in the work of Hua and wang explained this for similar structure formulated from grafted sodium alginate with polyacrylic acid in the presence of sodium humate and described the adverse effect of the sodium humate, which is similar in its structure to fulvic acid, by acting as a filler at higher contents [50].

Fig. 5 shows the steps that took place for developing the interpenetrating superabsorbent structure. KPS as an initiator attacks the backbone of the cellulose and works principally on the surface hydroxyl groups. Radicals are created as a result of this attack. The radicals produced can start the graft polymerization of acrylic acid onto the backbone surface. Some hydroxyl groups can be reacted directly with fulvic acid as well as acrylic acid forming ester linkages. This leads to a reactive surface on the cellulose backbone. The linked acrylic acid still has the chance for free radical copolymerization by the free initiating species in the medium or via coupling with another growing chain. An esterification reaction between a linked fulvic acid on the cellulose backbone and free acrylic acid in the medium is also possible. Such reactions especially in the presence of a difunctional monomer like methylenebisacrylamide gives a high probability for formation of interpenetrating network bearing high content of reactive groups.

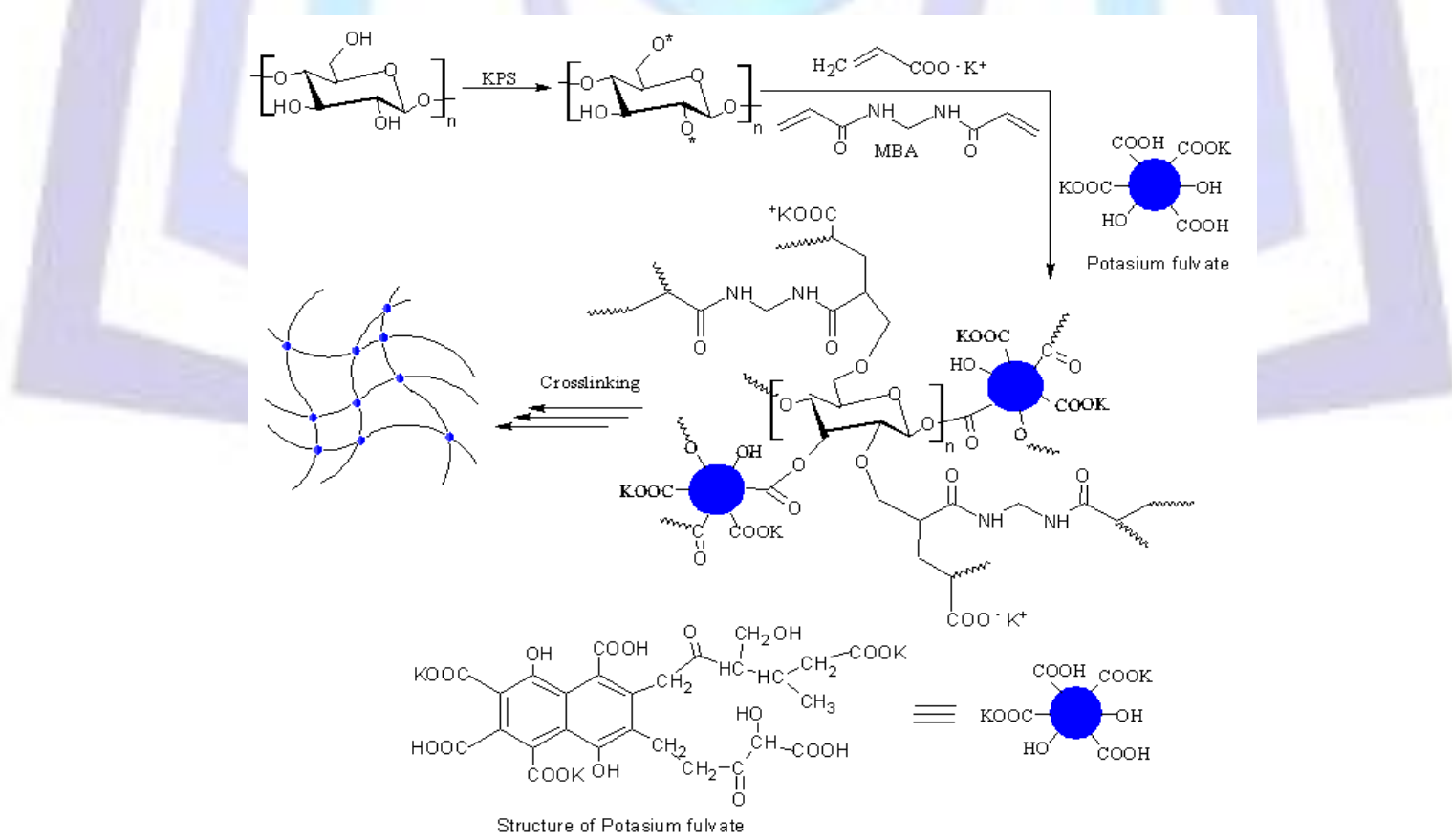

Fig. 5: A representation for the steps involved in the buildup of of the interpenetrating network structure.

\section{5 $\mathrm{Cu}^{2+}$ ion uptake}




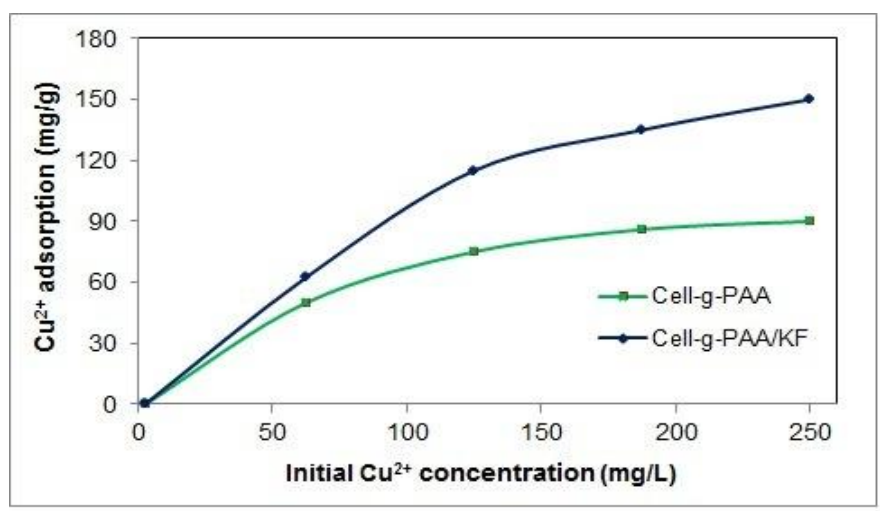

Fig. 6: Effect of Initial $\mathrm{Cu}^{2+}$ concentration on its adsorption by Cell-g-PAA and Cell-g-PAA/KF superabsorbents.

It is well known that the structural characteristics of polymeric backbones can strongly influence their potential to uptake metal ions. The efficiency of the prepared grafted cellulose with and without potassium fulvate for removal of metal ions from solution was examined. The amount of $\mathrm{Cu}^{2+}$ ion uptake by coordination to the active sites of the networks is disclosed in Fig. 6 which proves superiority of the modified network driven by the incorporated fulvic acid that contains more carboxyl and hydroxyl groups and thereby a stronger tendency to chelate metal ions [36, 43, 51]. This can be considered as an indirect proof for enhanced chemical activity after the insertion of fulvic acid salt as permanent part of network structure.

\subsection{Effect of pH on the swelling}

The water absorption of the grafted cellulose with polyacrylic acid was investigated in comparison with the same graft copolymer but after modification with fulvic acid as shown in Fig. 7. Generally, both structures behaved the same while the difference was in the level of water absorption at the different $\mathrm{pH}$ values. Cell-g-PAA acquired maximum absorption of 384 $\mathrm{g} / \mathrm{g}$ at $\mathrm{pH} 8$ while the minimal absorption, $10 \%$, was noticed at $\mathrm{pH} 2$. After the modification of the graft network with the potassium salt of fulvic acid (Cell-g-PAA-KF), it can be noticed that there was slight increase in the absorption in the acid range below $\mathrm{pH} 6$. At $\mathrm{pH} 6$, the water absorption increased by $22 \%$ while this enhancement was only $18 \%$ at $\mathrm{pH} 8$, lessened to $7 \%$ at $\mathrm{pH} 10$. This difference in the water absorption reveals some change in the network activity after the insertion of the fulvic acid to the network structure. At low pH values (below 6 ) the concentration of $\mathrm{H}^{+}$is high thus a major part of carboxylate groups are protonated form which hinders the anion-anion electrostatic repulsion.

Above $\mathrm{pH} 6$ and up to $\mathrm{pH} 8$, the carboxylate centers convert to $\mathrm{COO}^{-}$resulting higher electrostatic repulsion and this translates into larger absorption capacity. Increasing to $\mathrm{pH}$ beyond 8 decreases the swelling as there is a high content of $\mathrm{K}^{+}$ions which interferes with the anion-anion repulsion. Greater carboxylate ions content within the network structure leads to a drop in the potential of water absorption and increases leakage of water from the network due to the damaged possibility of hydrogen bond formation between water and carboxylate centers which causes collapse of the network [51].

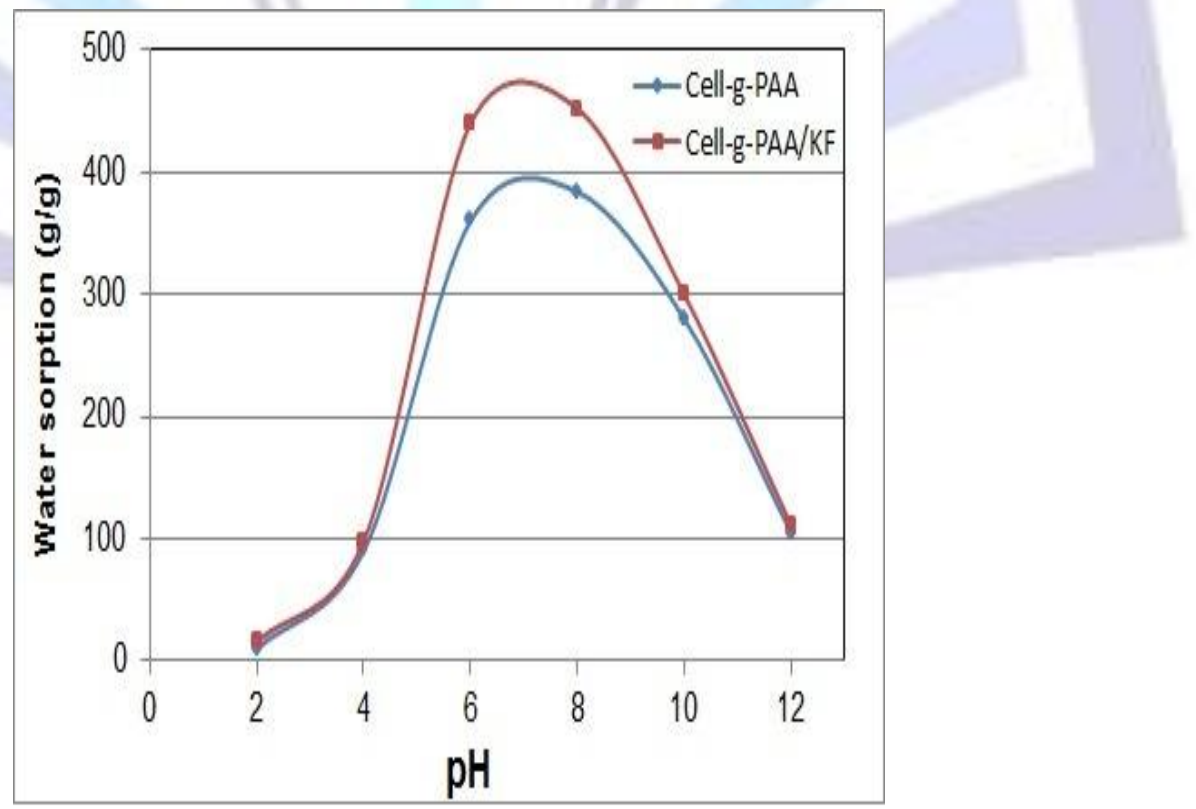

Fig. 7: Effect of $\mathrm{pH}$ on the swelling potential of Cell-g-PAA and Cell-g-PPA/KF. 


\subsection{Effect of salt solutions on the swelling}

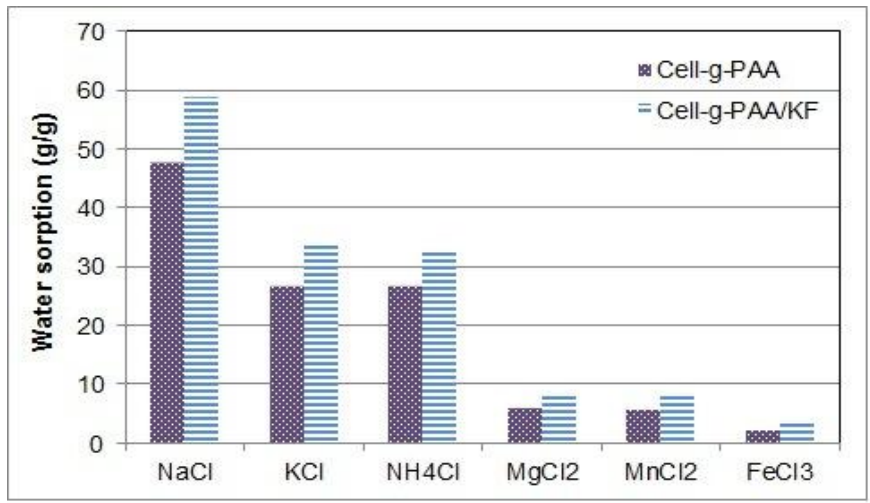

Fig. 8: Effect of various salts (0.15M) on the water absorbency.

Fig. 8 demonstrates how the water absorption of the prepared network structures are affected in the presence of salts in the absorption media. Cell-g-PAA acquired water absorption of $48 \mathrm{~g} / \mathrm{g}$ against $59 \mathrm{~g} / \mathrm{g}$ for Cell-g-PAA-KF in presence of $\mathrm{NaCl}$. In case of $\mathrm{KCl}$, they acquired absorption levels of $27 \mathrm{~g} / \mathrm{g}$ and $34 \mathrm{~g} / \mathrm{g}$, respectively, which was almost the same in the presence of $\mathrm{NH}_{4} \mathrm{Cl}$. There were remarkable drop in the water absorption in the presence of $\mathrm{MgCl}_{2}$ and $\mathrm{MnCl}_{2}$. $\mathrm{However}$ the drop was serious in case of $\mathrm{FeCl}_{3}$. It is obvious that the incorporation of fulvic acid to the network structure plays a role to counteract the bad effect of the salts on the water absorption, and this role is ruined as long as the valency of the metal ions increases. This can be justified by charge screening in case of the monovalent cations, while in case of the divalent cations, complexation of the carboxylate groups with these cations creates crosslinking that hinders the expansion of these structures. When $\mathrm{FeCl}_{3}$ is present, the crosslinking intensifies due to its trivalency and consequent increased electrostatic attraction with the anionic center of the network structure [52-54]

\subsection{Water retention behavior of Cell-g-PAA/KF-NPK superabsorbent composite in soil}

The better ability of the superabsorbent, Cell-g-PAA/KF, with respect to the other superabsorbents, it was loaded with NPK nutrients and the water retention in soil was explored at room temperature and $31 \%$ humidity. The soil ability to retentive the water was also considered for comparison (Fig. 9). After 28 days, the soil containing the superabsorbent showed slightly larger capacity of water retention as compared to the soil alone and the obtained retention levels were very close to similar superabsorbents built up from the graft polymerization of acrylic acid onto a backbone of chitosan coupled chemically to cellulose [55]. This confirms the role played by superabsorbents in soil to delay the water evaporation [56, 57].
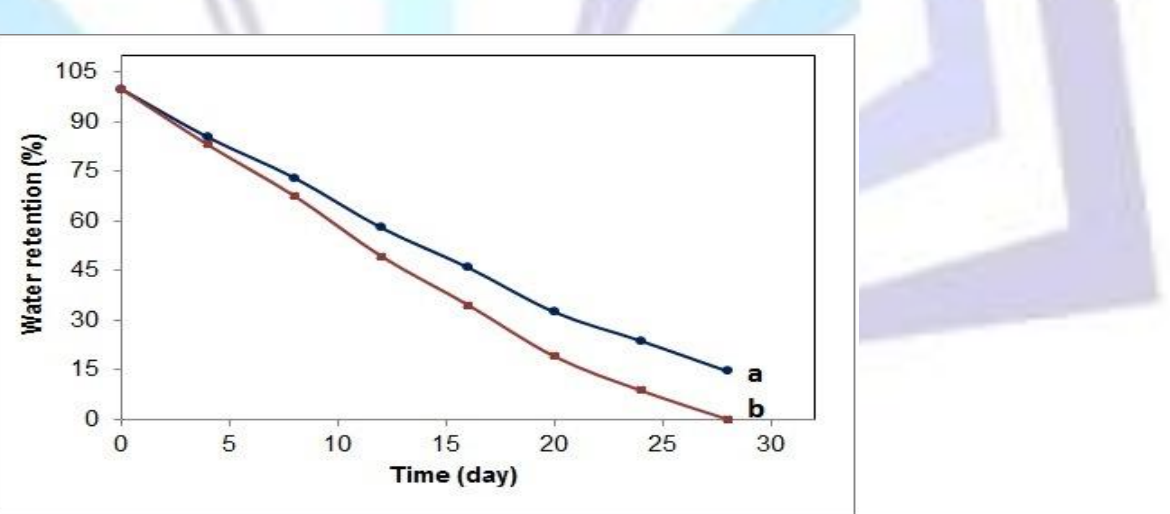

Fig. 9: The water retention of (a) soil with the superabsorbent Cell-g-PAA/KF-NPK and (b) soil.

\subsection{Fertilizer release in soil}

The release of NPK from superabsorbent polymers is affected by the soil type, cation exchange capacity (CEC), the water content and concentration of NPK. CEC seems to be a dominating parameter in this study as potassium a major part of the network structure after being inserted as a salt of both acrylic and fulvic acids during the polymerization.

Figs. 10-12 display the release of the nutrients from the superabsorbents in comparison with the direct release from free NPK. Fig. 10b reveals a steady release of N, namely $13.82 \%, 27.42 \%$ and $74.03 \%$ after 3, 5 and 30 days, respectively. In case of $\mathrm{P}$ (Fig. 11b), the corresponding released values were in the order of $12.42 \%, 25.43 \%$ and $71.56 \%$, respectively, while the $\mathrm{K}$ levels were $12.94 \%, 26.64 \%$ and $72.23 \%$ after the same time intervals (Fig. 12b). This ensures the adherence of these devices to the regulations the European Committee of Normalization (ECN) which states that the total released levels of NPK should neither exceed $15 \%$ after 3 days nor $75 \%$ after 30 days [58, 59]. On the 
contrary the release from the free NPK samples exhibited more than $85 \%$ within 3 days (Figs. 10-12a) which indicate the uncontrollable liberation of the fertilizers in absence of the superabsorbent.

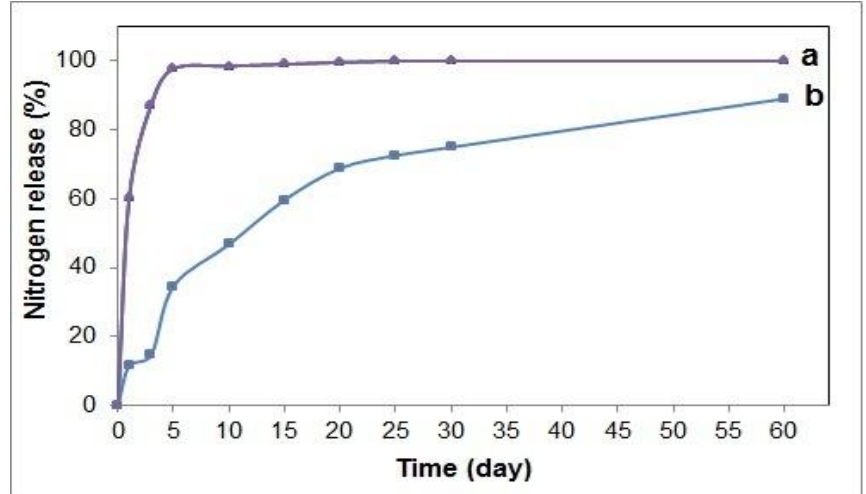

Fig. 10: Slow release of nitrogen in soil from (a) Cell-g-PAA/KF-NPK superabsorbent composite compared to (b) free NPK fertilizer.

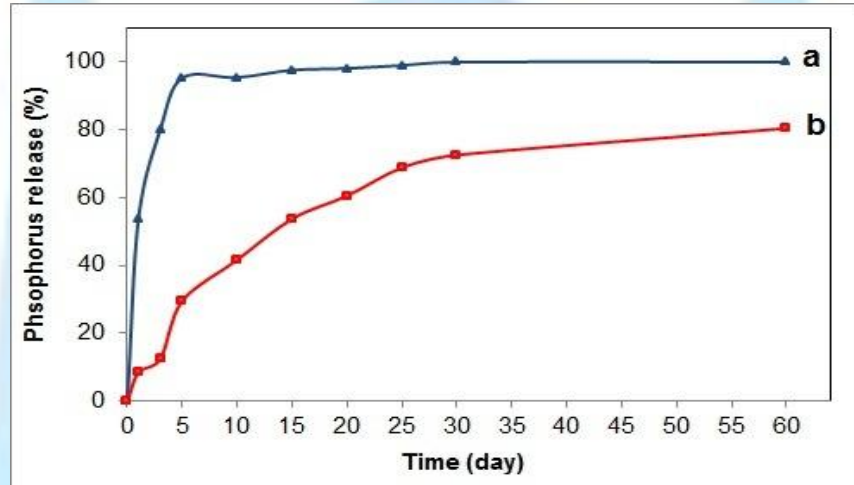

Fig. 11: Slow release of phosphorus in soil from (a) Cell-g-PAA/KF-NPK superabsorbent composite compared to (b) free NPK fertilizer.

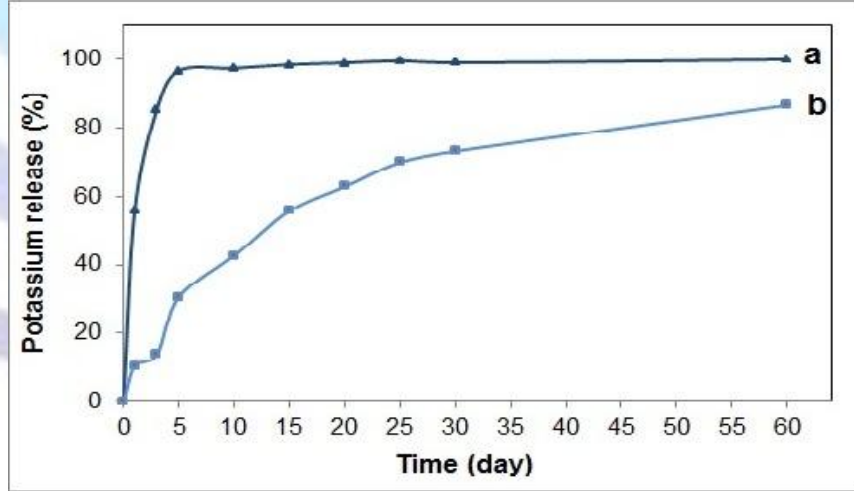

Fig. 12: Slow release of potassium in soil from (a) Cell-g-PAA/KF-NPK superabsorbent composite compared to (b) free NPK fertilizer.

\section{CONCLUSIONS}

Grafting polymerization of hydrophilic monomers like acrylic acid onto cellulose in presence of a crosslinking agent and fulvic acid derivative can yield a semi-interpenetrating superabsorbent with enhanced chemical activity as a result of the greater content of reactive groups such as $-\mathrm{COOH}$ and $\mathrm{OH}$. The produced structures are exhibiting variable tendency of water absorption over a wide range of $\mathrm{pH}$ values as a result of the acquired chemical modification by the insertion of $\mathrm{KF}$, which can be additionally translated into incremented water absorption and elevated potential to uptake $\mathrm{Cu}^{2+}$ from its solution. The enrichment of the chemical structure and broadening of its chemical environment enhanced also the possibility of its application as devices for controlled release of soil nutrients and improved capacity to hold the water preventing its evaporation. 


\section{ACKNOWLEDGMENTS}

We express our sincere thanks to Delta Agrochemicals Company for providing financial support for this work.

\section{REFERENCES}

[1] Pal, K., Banthia, A. K. and Kmajumdar, D. (2009). Polymeric Hydrogel: Characterization and Biomedical ApplicationsA mini review. Designed Monomers and Polymers, 12, 197-220.

[2] Murdan, S. (2003). Electro-responsive drug delivery from hydrogels. J. of Controlled Release, 92, 1-17.

[3] Peppas, N. A., Bures, P., Leobandung, W. and Ichikawa, H. (2000). Hydrogels in pharmaceutical formulations. European J. of Pharmaceutics and Biopharmaceutics, 50 (1), 27-46.

[4] Essawy, H. A. and Ibrahim, H. S. (2004). Synthesis and characterization of poly(vinylpyrrolidone-co-methylacrylate) hydrogel for removal of heavy metal ions from water, React. Funct. Polym. 61 (3), 421-432.

[5] Hoffman, A. S. (2002). Hydrogels for biomedical applications. Advanced Drug Delivery Reviews, 43, 3-12.

[6] Sannino, A., Demitri, C. and Madaghiele, M. (2009). Biodegradable cellulose-based Hydrogels: Design and Applications. Materials, 2, 353-373.

[7] Buchholz, F. L., Graham, A. T. (1997). Modern Superabsorbent Polymer Technology. In John Wiley \& Sons Inc., New York.

[8] Chang, C., Duan, B., Cai, J. and Zhang, L. (2010). Superabsorbent hydrogels based on cellulose for smart swelling and controllable delivery. European Polymer J., 46, 92-100.

[9] Shavit, U., Reiss, M. and Shaviv A. (2003). Wetting mechanisms of gel-based controlled-release fertilizers. J. of Controlled Release, 88, 71-83.

[10] Helaly, F. M., Essawy, H. A., El-Nashar, D. E. and Maziad N. A. (2005). Slow release of urea as a source of nitrogen from some acrylamide and acrylic acid hydrogels. Polym. Plast. Techn. Eng., 44, 253-263.

[11] Gross, R. A. and Kalra, B. (2002). Biodegradable Polymers for the Environment. Science, 297 (5582), 803-803.

[12] Pan, S. and Ragauskas, A. J. (2012). Preparation of superabsorbent cellulosic hydrogels. Carbohydrate Polymers, $87,1410-1418$.

[13] Khullar, R., Varshney, V. K., Naithani, S. and Soni P. L. (2008). Grafting of acrylonitrile onto cellulosic material derived from bamboo (Dendrocalamus strictus). eXPRESS Polymer Letters, 2 (1), 12-18.

[14] Thompson, T. T., Bastarrachea, M. I. L. and Vega, M. J. A. (2005). Characterization of henequen cellulose microfibers treated with an epoxide and grafted with poly(acrylic acid). Carbohydrate Polymers, 62, 67-73.

[15] Li, A., Zhang, J. and Wang, A. (2007). Utilization of starch and clay for the preparation of superabsorbent composite. Bioresource Technology, 98, 327-332.

[16] Athawale, V. D. and Lele, V. (1998). Graft copolymerization onto starch. II. Grafting of acrylic acid and preparation of its hydrogels. Carbohydrate Polymers, 35, 21-27.

[17] Kiatkamjornwong, S., Chomsaksakul, W. and Sonsuk, M. (2000). Radiation modification of water absorption of cassava starch by acrylic acid/acrylamide. Radiation Physics and Chemistry, 59, 413- 427.

[18] Li, X., Li, Q., Su, Y., Yue, Q., Gao, B. and Su, Y. (2015). A novel wheat straw cellulose-based semi-IPNs superabsorbent with integration of water retaining and controlled release fertilizers. J. of the Taiwan Institute of Chemical Engineers, 55, 170-179.

[19] Abe, K. and Yano, H. (2011). Formation of hydrogels from cellulose nanofibers. Carbohydrate Polymers, 85, $733-737$.

[20] Ye, D. and Yang, J. (2015). Ion-responsive liquid crystals of cellulose nanowhiskers grafted with acrylamide. Carbohydrate Polymers, 134, 458-466.

[21] Pourjavadi, A., Harzandi, A. M. and Hosseinzadeh, H. (2004). Modified carrageenan 3. Synthesis of a novel polysaccharide-based superabsorbent hydrogel via graft copolymerization of acrylic acid onto kappa-carrageenan in air. European Polymer J., 40, 1363- 1370.

[22] Yamamoto, H., Amaike, M., Saitoh, H. and Sano, Y. (2000). Gel formation of lignin and biodegradation of the lignin gels by microorganisms. Materials Science and Engineering, C 7, 143- 147.

[23] Raschip, I. E., Hitruc, E. G., Oprea, A. M., Popescu, M. C. and Vasile C. (2011). In vitro evolution of the mixed xanthan/lignin hydrogels as vanillin carriers. J. of Molecular Structure, 1003, 67- 74.

[24] Don, T. M., Chuang, C. Y. and Chiu, W. Y. (2002). Studies on the Degradation Behavior of Chitosan-g-Poly(acrylic acid) Copolymers. Tamkang J. of Science and Engineering, 5 (4), 235-240.

[25] Xie, Y. T. and Wang A. Q. (2010). Preparation and Swelling Behaviour of Chitosan-g-poly(acrylic acid)Muscovite Superabsorbent Composites. Iranian Polymer J., 19 (2), 131-141. 
[26] Zheng, Y., Zhang, J. and Wang A. (2009). Fast removal of ammonium nitrogen from aqueous solution using chitosan-g-poly(acrylic acid)/attapulgite composite. Chemical Engineering J., 155, 215- 222.

[27] Liu, J., Li, Q., Su, Y., Yue, Q., Gao, B. and Wang, R. (2013). Synthesis of wheat straw cellulose-g-poly(potassium acrylate)/PVA semi-IPNs superabsorbent resin. Carbohydrate Polymers, 94, 539-546.

[28] Liang, R., Yuan, H., Xi, G. and Zhou, Q. (2009). Synthesis of wheat straw-g-poly(acrylic acid) superabsorbent composites and release of urea from it. Carbohydrate Polymers, 77, 181-187.

[29] Liu, Z., Miao, Y., Wang, Z. and Yin, G. (2009). Synthesis and characterization of a novel superabsorbent based on chemically modified pulverized wheat straw and acrylic acid. Carbohydrate Polymers, 77, 131- 135.

[30] Ren, J., Kong, W. and Sun, R. (2014). Preparation of Sugarcane Bagasse/Poly(Acrylic Acid-co-Acryamide) Hydrogels and their Application. BioResources, 9 (2), 3290-3303.

[31] Hu, X., Hu, K., Zeng, L., Zhao, M. and Huang, H. (2010). Hydrogel prepared from pineapple peel cellulose using ionic liquid and their characterization and primary sodium salicylate release study. Carbohydrate Polymers, 82, 62-68.

[32] Bardajee, G. R., Pourjavadi, A., Soleyman, R. and Sheikh, N. (2008). Irradiation mediated synthesis of a superabsorbent hydrogel network based on polyacrylamide grafted onto salep. Nuclear Instruments and Methods in Physics Research, B 266, 3932- 3938.

[33] Banerjee, S., Verma, S., Pal, D., Ghosh, A. K., Bhattacharya, S. S., Chattopadhyay, P., Ghosh, A. and Kaity, S. (2011). Fabrication and assessment of polyacrylate/(guar gum modified bentonite) superabsorbent polymeric composite. J. Polymer Engineering, 31, 567-575.

[34] Barihi, R., Panahour, E. and Beni, M. H. M. (2013). Super Absobent Polymer (Hydrogel) and its Application in Agriculture. World of Science J., 1 (15), 223-228.

[35] Ekebafe, L. O., Ogbeifun, D. E. and Okieimen, F. E. (2011). Polymer Applications in Agriculture. Biokemistri, 23 (2), 81-89.

[36] Zheng, Y., Hua, S. and Wang, A. (2010). Adsorption behavior of $\mathrm{Cu}^{2+}$ from aqueous solutions onto sarch-gpoly(acrylic acid)/sodium humate hydrogels. Desalination, 263, 170-175.

[37] Liu, J., Wang, Q. and Wang, A. (2007). Synthesis and characterization of chitosan-g-poly(acrylic acid)/ sodium humate superabsorbent. Carbohydrate Polymers, 70, 166-173.

[38] Lotfi, R., Pessarakli, M., Kouchebagh, P. G. and Khoshvaghti, H. (2015). Physiological responses of Brassica napus to fulvic acid under water stress: Chlorophyll a fluorescence and antioxidant enzyme activity. The Crop J., 3, 434-439.

[39] Wang, S. G., Sun, X. F., Liu, X. W., Gong, W. X., Gao, B. Y. and Bao, N. (2008). Chitosan hydrogel beads for fulvic acid adsorption: Behaviors and mechanisms. Chemical Engineering J., 142, 239-247.

[40] Hiradate, S., Yonezawa, T. and Takesako, H. (2006). Isolation and purification of hydrophilic fulvic acids by precipitation. Geoderma, 132, 196-205.

[41] Wang, W., Zhen, W., Bian, S. and Xi, X. (2015). Structure and properties of quaternary fulvic acid -intercalated saponite/poly(lactic acid) nanocomposites. Applied Clay Science, 109-110, 136-142.

[42] Ofomaja, A. E., Ngema, S. L. and Naidoo, E. B. (2012). The grafting of acrylic acid onto biosorbents: Effect of plant components and initiator concentration. Carbohydrate Polymers, 90, 201-209.

[43] Nada, A. M. A., Alkady, M. Y. and Fekry, H. M. (2007). Synthesis and characterization of grafted cellulose for use in water and metal ions sorption. BioResources; 3 (1), 46-59.

[44] Tung, N. T. and Khoi, N. V. (2010). Kinetics and mechanism of graft polymerization of acrylic acid onto starch initiated with ceric ammonium nitrate. J. of Chemistry, 48 (5), 621-626.

[45] Ali, P. and Rouhollah, S. (2010). Novel high capacity swelling superabsorbent composite and its potential for controlled release of fertilizers. Iranian J. Chemical Chemistry Engineering, 29 (4), 113-122.

[46] Wu, L. and Liu, M. (2008). Preparation and properties of chitosan-coated NPK compound fertilizer with controlledrelease and water-retention. Carbohydrate Polymers, 72, 240- 247.

[47] Zhong, K., Lin, Z. T., Zheng, X. L., Jiang, G. B., Fang, Y. S., Mao, X. Y. and Liao, Z. W. (2013). Starch derivativebased superabsorbent with integration of water-retaining and controlled-release fertilizers. Carbohydrate Polymers, 92, 1367-1376.

[48] Zhan, F., Liu, M., Guo, M. and Wu, L. (2004). Preparation of superabsorbent polymer with slow -release phosphate fertilizer. J. of Applied Polymer Science, 92, 3417-3421.

[49] Giovanela, M., Parlanti, E. Soriano-Sierra, E. J., Soldi, M. S. and Sierra M. D. (2004). Elemental compositions, FT-IR spectra and thermal behavior of sedimentary fulvic and humic acids from aquatic and terrestrial environments. Geochemical J., 38, 255-264. 
[50] Hua, S. and Wang, A. (2009). Synthesis, characterization and swelling behaviors of sodium alginate-g-poly(acrylic acid)/sodium humate superabsorbent. Carbohydrate Polymers, 75 (1), 79-84.

[51] Chauhan, G. S., Singh, B. and Kamar, S. (2005). Synthesis and characteristics of N-vinyl pyrrelidine and cellulose based functional graft copolymer for use as metal ion and iodine sorbent. J. of Applied Polymer Science, 98, 373-383.

[52] Rashidzadeh, A. and Olad, A. (2014). Slow-released NPK fertilizer encapsulated by NaAlg-g-poly(AA-co-AAm)/MMT superabsorbent nanocomposite. Carbohydrate Polymers, 114, 269-278.

[53] Bao, Y., Ma, J. and Li, N. (2011). Synthesis and swelling behaviors of sodium carboxymethyl cellulose-g-poly(AA-coAM-co-AMPS)/MMT superabsorbent hydrogel. Carbohydrate Polymers, 84 (1), 76-82.

[54] Marandi, G. B., Mahdavinia, G. R., and Ghafary, S. (2011). Collagen-g-poly(sodium acrylate-co-acrylamide)/sodium montmorillonite superabsorbent nanocomposites: Synthesis and swelling behavior. J. of Polymer Research, 18 (6), 1487-1499.

[55] Essawy, H. A., Ghazy, M. B. M., El-Hai, F. and Mohamed M. F. (2015). Novel chitosan-cellulose backbone for grafting polymerization of acrylic acid and application in controlled release. J. of Chemistry and Chemical Sciences, 5 (12), 698-712.

[56] Ni, B., Li, M. and Lu, S. (2009). Multifunctional slow-release urea fertilizer from ethylcellulose and superabsorbent coated formulations. Chemical Engineering J., 155, 892-898.

[57] Rashidzadeh, A. and Olad, A. (2014). Slow-released NPK fertilizer encapsulated by NaAlg-g-poly(AA-co-AAm)/MMT superabsorbent nanocomposite. Carbohydrate Polymers, 114, 269-278.

[58] Trenkel, M. E. (1997). Controlled release and Stabilized Fertilisers in Agriculture. IFA, Paris.

[59] Smith, J. D. and Harrison, H. C. (1991). Evaluation of polymers for controlled release properties when incorporated with nitrogen fertilizer solutions. Communications in Soil Science and Plant Analysis, 22 (5-6), 559-573. 